\section{OPTIMIZING LEISURE EXPERIENCE AFTER 40}

\section{OPTIMIZANDO LA EXPERIENCIA DE OCIO DESPUÉS DE LOS 40}

\author{
Douglas A. Kleiber \\ University of Georgia, USA \\ dkleiber@uga.edu.
}

\begin{abstract}
RESUMEN: Envejecer es un proceso natural que ocurre a lo largo de toda la vida; no obstante, sugerir que algunas personas envejecen más exitosamente que otras es advertir ciertos criterios para vivir bien al final de la vida $y$, acto seguido, considerar los factores que contribuyen a ello. En este artículo se sitúa al ocio como frente y eje central del proceso de envejecimiento -especialmente tras la mediana edad-, identificándose aquellos aspectos de la experiencia del ocio que pueden ser más influyentes. En este sentido, se parte de los estándares provistos por modelos de envejecimiento exitoso, reconociéndose sus oportunidades y posibilidades (incluso para quienes parten con desventaja en este proceso), indagando en las experiencias críticas que han podido ser más influyentes durante el período adulto inmediatamente anterior, y considerando el implicarse -o no- como procesos y experiencias que optimizan el ocio y, por extensión, el envejecimiento. Asimismo, se atiende a la participación cívica y social con base en los modelos de adaptación y selección de los psicólogos evolutivos Paul y Margaret Baltes y Leah Carstenson.
\end{abstract}

PALABRAS CLAVE: Ocio; edad madura; experiencia óptima.

The beauty of leisure throughout life is that it can be shaped to one's desire in an infinite variety of ways. But do people take full advantage of the opportunities, even in their later years when they have more time? Most indications are that they do not. Whether it is for lack of appropriate models or lack of preparation for using time wisely (as opposed to efficiently), many reach the second half of life with only an expectation for rest and pleasure, the primary rewards for having worked to carve out a sufficient standard of living and/or establish a family with a firm foundation. Instead, the most common pattern of older people in the western world - even those with circumstances that afford the freedom to choose to the contrary - is to spend massive amounts of time watching television (e.g., Robinson \& Godbey, 1997). And while television at times may be intriguing and meaningful as well as relaxing and pleasurable, the evidence is that it lacks the experiential impact that would contribute to well being in later life (e.g., Kubey \& Csikszentmihalyi, 1990). But what is "using time wisely"? Surely, that is

\begin{abstract}
Aging is a natural process that occurs across the lifespan, but to suggest that some people age more successfully than others is to invoke some criteria of living well in later life and then to consider the factors that may contribute. This article puts leisure front and center in the aging process, especially after midlife, and identifies experiential aspects of leisure that may be most influential. But it departs from some of the standard models of successful aging in recognizing opportunities and possibilities even for those with disabling conditions, in reaching back earlier in adulthood for critical incidents that may prove influential, and in considering disengagement as well as engagement as processes and experiences for optimizing leisure and thus aging. Relying more on models of adaptation and selectivity from developmental psychologists Paul and Margaret Baltes and Leah Carstenson, social and civic engagement are considered as well.
\end{abstract}

KEY WORDS: Leisure; later life; optimal experience.

a personal value judgment. And are not relaxation and pleasure as defensible as anything else? Perhaps, but to better answer that question we would need to consider their place in the research on what it means to age well or to age successfully.

What I will argue in this article is that we do have examples and evidence for patterns that are sustaining and enriching in adulthood and contribute substantially to subjective well being, quality of life and perhaps even quantity of life, though that isn't the critical measure in my view. We must be more precise about the indicators of successful aging before examining how and when leisure choices can contribute to those ends. Before that however, we can begin by acknowledging who might be left out of this analysis. The topic of leisure and free time opportunities is arguably irrelevant to the poor and the ill and disabled for whom survival is an ongoing struggle itself, where pleasures are few and opportunities for self-realization are limited. As one person pointed out, there are places on this 
planet - even in the most developed of countries - where the notion of "lifestyle" is irrelevant since it depends on some degree of freedom, choice and opportunity, and many people seem to have none. But what is equally clear is that people often find ways to make even the most difficult lives enjoyable and meaningful; and in doing so they give us pause to reconsider the prevailing notions of successful aging and leisure and their relationship. The primary questions to be addressed in this article, then, are what when, what and how does leisure activity and experience contribute to successful aging?

\section{SucCESSFUL AgING}

Successful aging has been defined in a variety of ways (cf. Bowling, 2007; Phelan \& Larson, 2002; Rowe \& Kahn, 1997). Longevity is commonly used and of course that also implies the relative absence of disease and illness that threaten survival. But most who consider successful aging consider the quality more than the quantity of life, and matters of subjective well being are prominent. Furthermore, we would depart from the more purely actuarial thinking in looking at aging as a process that begins earlier in life, especially when one begins to think of life left to live, a common switch in perspective (versus time since birth) that occurs at midlife (Neugarten, 1977). And as noted, there are those for whom chronic health problems or various environmental circumstances might predict a shorter than average lifespan who may nevertheless age successfully by making the most of what they have.

If aging successfully $1 \mathrm{~s}$ a matter of adapting effectively to whatever one has, then one of the most compelling contemporary models of successful aging is that of Selective Optimization with Compensation (Balters \& Baltes, 1990; 1998 Baltes \& Carstensen, 1996). Optimization is about "making the best of things" whatever the conditions; but the model also recognizes that to do so may require being discriminating and selective about making behavioral choices (and even choosing among companions) so as not to deplete the resources necessary to enable optimization. Indeed, some disengagement from roles and activities that have lower priority with respect to meaning, enjoyment and contribution to well being may be necessary. Disengagement thus has some recognized value in this model whereas tends to be discredited in other views of successful aging. Nevertheless, the model allows for change and innovation as well in allowing for "elective" selection - choosing to do new things - as well as "loss based" selection that is normally a matter of disengagement from patterns of activity and interaction that were formerly but are now no longer valued. Finally the model emphasizes compensation in finding ways to continue with that which is still desired or to initiate activities that may take one in a new direction. Baltes and Baltes (1990) use the example of a famous pianist composer who chooses to play slower pieces as his reaction time diminishes and to vary his practice regimens so as to conserve the necessary capacity to conform. Other forms of compensation rely on support from others and assistive technology and often show up in the form of modifications to patterns of physical activity and sport, such as in playing doubles rather than singles or in relying on a neighbor for transportation to and from the community center fitness facility. Examples can of course be found in almost any activity that demands some degree of skill.

In our studies of leisure in coping with negative life events (Kleiber et al., 2002), such as a paralyzing automobile accident or the loss of a loved one, that can occur throughout the life course, we found remarkable examples of resilience, persistence and even personal transformation in finding the most appropriate sources of enjoyment and self-expression under the circumstances. A return to formerly valued activities was obviously a sign of triumph, however much it had to be modified (e.g., a woodworker who needed a new bench arrangement after a spinal cord injury) as was using the event to make a turn in the road to do something entirely new. But there were also signs of favorable adjustment - and even successful aging - in just finding the resumption of older feelings of joy associated with very simple activities such as viewing a sunset (Hutchinson \& Kleiber, 2005). Life can, after all, be sweet at times for nearly anyone. And attitude may be critical in providing perspective on the challenges that just living generates.

While distraction from the pain of illness and loss, and even recovery of some sense of joy in life may thus be adaptive in the coping process; it may be hard to associate them with successful aging. Nevertheless, the resiliency suggested in effective coping may well be the key to be- 
ing adaptive - and happy - in later life. Subjective well being - whether a matter of happiness, life satisfaction or just the relative balance of more positive than negative affect - figures prominently in perspectives on successful aging (e.g., Vaillant, 2002).

Perhaps the SOC model and ideas about coping with stress and loss merely identify the important processes associated with successful aging. Where might we look, for the meaning, the substance, of experience that is most impactful in later life - that would define the endpoints of effective adaptation and be the source material for subjective well-being? One place to start would be age-related developmental tasks. Erik Erikson $(1963,1982)$ provided one of the most highly regarded theoretical templates of the important issues of the life span. With respect to adulthood he offered three principle tasks: establishing intimacy (pair bonding) in early adulthood, generativity (contribution to posterity) in middle age and personal integration (acceptance of what has been) in later life. We will consider each of these further; but since they were proffered by Erikson the world has changed somewhat and followers have insisted that there are other predictable issues in adulthood that are not reflected in those three. Antonovsky and Sagy (1990), for example, argued that retirement in particular serves as a pivotal point for addressing the crisis of engagement versus disengagement; and they advanced four specific tasks that must be addressed as a result:

1) finding active involvement (how active should I be? How should I be active? what isto be done);

2) reevaluation of life satisfaction (what is personally worth doing);

3) reevaluation of a world view (finding sense of coherence, meaning, purpose... what isthe purpose of my life?; how should it be approached?); and

4) sense of health maintenance (how do I protect against vulnerability?).

\section{Presumably, successful aging Would Be ReFLected, AT LEAST PARTLY, IN THE POSITIVE RESOLUTION OF THESE QUESTIONS}

The case for expanding on Erikson's model is made a part with recognition of the fact that having 5 of 8 crises occurring before the age of 18 and 3 for the rest of life seemed rather unbalanced and misrepresentative of the "seasons" of adulthood (cf. Levinson et al., 1978); that people are living longer and retiring earlier than was the case when Erikson was writing; and that as a result there is a case to made, especially for the "third age" (relatively recently retired young-old) as being distinctly different from the needs and opportunities of a fourth and final age. And cohort differences, such as those associated with the large "Baby Boom" cohort that emerged after World War II, might well require different models.

That also raises the question of whether there is any more general truth to those models; do they represent anything more that the white, western middle class culture surrounding authors and investigators at the times they were developed. Antonovsky and Sagy's revision of Erikson's model appears to apply rather exclusively to Israeli culture and to reflect a strong work ethic; but even in seeing its application to other Western countries like the US and the UK for example, that still leaves the rest of the world at large unaccounted for. Such models have also been taken to task for both gender and social class biases. Indeed, a post modern interpretation of development would hold little stock in a predictable sequence of tasks or issues, such that one might regard their completion alone as a signs of successful aging. Still, we can use such ideas heuristically to assess goals and purposes that would help to define successful aging in a particular local at a particular time.

\section{The Contribution of Leisure}

How then might leisure contribute to such ends? As with the multiple ideas about successful aging, the many interpretations of leisure suggest a complex picture. And as was suggested at the outset, some leisure patterns, activities and experiences may offer little at all. Indeed, the boredom that can be associated with idleness, even if the time is "filled" with a low demand activity like television watching, may perpetuate or even lead to the kind of stagnation that Erikson suggested as the counterpoint to generativity, i.e. a failure to progress toward maturity in young and middle adulthood. The kind of boredom and ennui that may be reflected in idle diversion might seem to some to be hardly

ARBOR Vol. 188754 marzo-abril [2012] 341-349 ISSN: 0210-1963 
worthy of the name leisure but it nevertheless describes the free time activity of millions of people.

By contrast, gerontologists often speak of the place of "valued activities" in the growth and subjective well being of older people. These valued and favorite activities, from gardening to sports and games to volunteer activities and involvement in voluntary associations, are generally patterns of engagement that are intrinsically motivated, self-determined and socially integrative. Perhaps it is this last feature - being socially integrative - that is most responsible for the evidence that activity involvement is generally associated with greater life satisfaction (Everard et al., 2000; Iwasaki \& Smale, 1998; Menec, 2003; Nimrod, 2007), certainly an important sign of successful aging.

Indeed, sometimes these valued activities are taken so seriously, are so intensely involving, and so demanding of attention and effort that they also have been recognized as a prototype of optimal experience (Csikszentmihalyi, 1990; Csikszentmihalyi \& Csikszentmihalyi, 1988). Serious leisure as Robert Stebbins has referred to it, following his studies of hobbyists, amateurs and volunteers (1982; 1992; 2000), requires effort and perseverance, connects one with other like-minded participants in a kind of social world, and may even offer a "career" of sorts. The source of satisfaction in such activities is primarily in the action of the activity, itself, where absorption occurs in a matching of one's skills with the challenges provided and the enjoyment comes through the wholehearted investment of attention and a feeling of flow. This focus on the activity at hand takes attention away from the usual subjects - time, the near environment, and one's self - and results in intense satisfaction and enjoyment. Such experience may be found in activities - such gambling and videogame involvement that may be designed just for that purpose - but when the activity seems to be personally meaningful, self-expressive and socially involving, it represents a pattern of growth and social integration that contributes measurably to subjective well being (e.g., Rousseau \& Vallerand, 2008).

It is noteworthy that volunteerism is also included in Stebbin's serious leisure perspective (1992a, 2007), but only when that volunteerism has "career" properties where one can proceed from "novice" involvement with just a sense of contributing to a degree of commitment and responsibility that has the properties of an intrinsically motivated job.
Certainly many types of volunteer activity fall short of this level and are only "serious" by virtue of the need being addressed; but in either case a sense of using one's time in "generative" ways redeems leisure that might otherwise be regarded as self-indulgent (Kleiber, 2011). That such activities also contribute to a sense of community and a sense of belonging should not be underestimated in terms of their potential to contribute to subjective well being as well (Musick \& Wilson, 2003; Okun \& Michel, 2006). Elsewhere (Maynard \& Kleiber, 2005) we have suggested that the kind of "civic friendship" that is created in such settings is important to development of social capital as well as self-actualization and subjective well being. But civic friendships may also be generated in simpler, less "constructive" ways... meeting with others at a café or a restaurant on a regular basis for example, as so many groups do in later life. Such events may lack the "flow" and identification properties of more serious involvement, but they may do as much for social integration and subjective well being in making people feel connected.

\section{Optimal Experience}

That also begs the question of "optimal" experience more generally. There is in serious leisure and flow the intensity of involvement, the performance and skill building capacity that is associated with personal growth, and even the quality of enjoyment that collectively seems to be optimal; but we should also look at "optimal" with respect to the potential for the generation of meaning. This idea would see leisure optimized in an even greater range of activities and experiences. Let me review three - relaxation, interest and savoring - that have been the subject of recent research in psychology while being largely neglected in leisure studies and gerontology.

Relaxation. Exploration and invested attention rely to a great extent on security and the absence of anxiety. When one relaxes in letting down psychologically and physically, disengaging from activity that has been preoccupying and effortful, there is the prospect for boredom and even sleep; but relaxed peacefulness opens one up to the world around. Barrett and Russell (1999) review research that demonstrates that positive affect can be associated with deactivation as well as activation. And 
of course, relaxation's connection to peacefulness has a traditional place in leisure scholarship (e.g., Pieper, 1962). Nevertheless, relaxation has been neglected among leisure researchers in recent years in spite of its significance and value (Kleiber, 2000).

Interest. What may be most important to leisure studies about relaxation, however, is its relevance for affording the experience of interest. Interest is what has been called a "knowledge emotion" (Silvia, 2008) - along with confusion, surprise, and awe - and it is one of the key orienting and activating aspects of leisure involvement. It occurs when one encounters novel, challenging or aesthetically pleasing activities or objects while promising the satisfaction of basic needs (Deci, 1992). It may itself be stimulated by activities that have some connection to one's existing dispositions and interests, as a kind of extensive process of self-discovery, or it may come about in response to attractive images that are entirely new, seeing someone else obviously enjoying an unfamiliar activity, for example (Kleiber, 1999). It is very likely to lead to more invested attention, but it precedes such involvement and is therefore distinguishable from it. Flow involves a narrower focus, which, as indicated, is usually a matter of chosen engagement and commitment. But the consideration of possibilities for engagement (including prospects for flow), involves an open focus that we sometimes associate with spontaneity and curiosity, with exploration and play.

On the other hand, flow may also lead to the consideration of alternatives, especially when it is ended with higher or lower than optimal challenge. Creativity may follow a period of intense absorption, where relaxation and "incubation" allows openness to new ideas. While flow takes advantage of increasing demand, within parameters, to stimulate skill development and growth, curiosity and interest are processes more akin to "listening" to the environment for new action possibilities. Indeed leisure may itself be construed as opportunity, opportunity to explore that which is intriguing and stimulating. While interest and flow may work in synchrony, they are distinguishable by the absence of goals in the former and clear goals and feedback for the latter. Existentially, this experience is associated with personal innovation as well as creativity. In studies of people recently retired, leisure was associated with opening up to new possibilities about the self as well as the rediscovery or reconstruction of old interests (Nimrod \& Kleiber, 2007).

Savoring. The third experience that is distinguishable from flow is that of savoring, a process by which people "bring about, appreciate and enhance positive experiences in life" (Bryant \& Veroff, 2007). Savoring is further characterized by sharing with others, memory building, self-congratulation, comparing, sensory and perceptual sharpening, temporal awareness, and counting blessings. Savoring is similar to flow in that it is a positive experience, but it is different in being about considering and reconsidering other experience, rather than having attention merged with action. It may come immediately after flow or the other experiences we have been discussing.

The authors consider it the positive equivalent of coping, which is about managing negative experiences. Savoring involves reflection with positive affect - in focusing on the future, with eager anticipation, or on the past, with pleasurable reminiscence, or on the present, with thoughts like "it doesn't get any better than this". In contrast to flow, which relies on a consolidation of action and awareness, savoring separates awareness from action in drawing an evaluation. As a kind of self-awareness it would in fact interfere with flow, making it less than optimal in situations calling for concentration such as a dismount from the parallel bars or having sexual intercourse. But it is common in many contexts, especially in leisure, as an expression of appreciation and gratitude.

Appreciation and gratitude are themselves well established concomitants of subjective well-being and happiness (e.g., Vaillant, 2002). Even when circumstances are not ideal, the evidence on post traumatic growth (Tedeschi \& Calhoun, 2004) and on coping with chronic illness (e.g., Nimrod \& Hutchinson, 2010) demonstrates the compelling value of reflection and appreciation and the potential role of leisure in realizing it. In their studies of accident and trauma victims and those who had suffered significant losses Tedeschi and Calhoun found that among the five most common components of positive adaptation was the awareness of "greater appreciation and changed priorities" typically manifested in an expanded commitment to live in the present and appreciate the immediate joys that life may bring. This posture is very much in line with a kind of relaxed and joyful openness that has been considered an 
essential quality of leisure by some (Pieper, 1965; Wilson, 1991). Pieper, for example, asserts that:

Leisure is an attitude of non-activity, of inward calm, of silence; it means not being 'busy' but letting things happen... Leisure is not the attitude of mind of those who actively intervene, but of those who are open to everything... of those who leave the reins loose and who are free and easy themselves" (p. 51-52).

Savoring also often involves the appreciation of others, of one's connectedness to family and friends and the world around, of relatedness and belonging. All this makes a case for savoring as another optimal experience and worthy of recognition and cultivation.

Relaxation, interest and savoring are optimal in ways other than is the case with "flow", but they do have their associations with positive emotion and to that extent may be adaptive and life-enhancing in important ways. It is also worth noting that the passions born out of flow experience can become psychologically threatening in some ways, in pathological gambling for example. The difference between being passionately "addicted" to an activity and compulsively controlled by its pleasures may be subtle at times, but it is real (Vallerand, 2010). And even when not compulsive, flow experience and serious leisure activities may be seductive in ways that interfere with other priorities (Stebbins, 1992b; Stenseng, 2008; Vallerand, 2010).

\section{Continuity versus Change}

As I have struggled to relearn the Spanish that I was introduced to with several years of formal instruction as a young person, I am reminded of the old saying, "You can't teach an old dog new tricks". I'm "only" 63 and Spanish is not exactly new to me, but language acquisition and an orientation to change and new learning clearly favor the young. Nevertheless there is considerable plasticity in the aging brain and the capacity for innovation and growth throughout the life span. And there is considerable evidence that innovation in valued activities is associated with subjective well being (e.g., Nimrod, 2008; Nimrod \& Kleiber, 2007). The caution here is that in being expansive one runs the risk of a kind of disintegrative effect that may undermine the kind of consolidation and integration favored by Erikson and others. Trying everything and committing to nothing might have the sometimes beneficial effect of keeping one busy and distracted, but it would likely perpetuate a dis-ease that is associated with the "busy ethic" that many have considered something close to a cultural neurosis (cf. Ekerdt, 1987; Katz, 2000; Tornstom, 2005) that may be most pernicious in later life, but has its seeds in earlier days. Leah Carstensen (1993) and her colleagues (Carstensen, Fung, \& Charles, 2003; Carstensen, Isaacowitz \& Charles, 1999) have found that acquiring new friends and different experiences is more common to the young who feel an infinite future, while to age successfully with a more finite future is to be more selective with activity choices and experiences, to abandon the contacts that may be interesting and novel but offer little of meaning, and to savor those that are tried and true.

In that regard the case for continuity may be stronger. There is the stabilizing "convoy" of activities and relationships (e.g., Kahn \& Antonucci, 1980) that seems to be associated most commonly with successful aging (e.g., Vaillant, 2002). And indeed, continuity of involvement in later life is more common and more highly associated with life satisfaction than is change. But perhaps best of all would be some combination, followed in accordance with the processes of socio-emotional selection, optimization, and compensation. Research that manages to more accurately assess the context of activity choices and experiences as well as their experience on subjective well being, is still needed.

\section{IMPLICATIONS}

Given that we have a variety of leisure experiences that we can point to in later life as optimal, when and how are they best employed to optimize aging itself? Allow me to be prescriptive and offer some strategies based on the literature and evidence reviewed above:

First, find flow wherever and whenever possible; but be cautious about over involvement and compulsive engagement.

Second, be cautions also about "putting all the eggs in one basket"; even if some activities are less enjoyable and engaging than others, a modest repertoire will cushion the 
blow if and when others are lost. Being "balanced investors" applies also to valued activities (Kelly, 1987).

Third, allow for relaxation, interest and savoring to be among the experiences that make leisure valuable in other ways. Relaxation speaks for itself, while interest is the starting point for finding meaning, and savoring offers perspective necessary to make the most of experiences that have happened, are happening, or will happen.

Fourth, judge the value of activities ultimately against other criteria. Do they represent "vital engagements" (Nakamura \& Csikszentmihalyi, that have existential significance as well as immediate gratification and the prospect for "flow"? Does it address developmental tasks? Does it contribute to social innovation or social integration?

Fifth, ask for help as needed. Leisure may be a gift, but it is easily squandered.
Advice and instruction may contribute to its optimization.

These strategies might find their way into intervention programs or established leisure education programs in community centers, but they are raised here as implications and extensions of other "non-leisure" research on human development and aging. Further research is clearly needed on the circumstances that call for greater engagement as well as those that would invite disengagement at least that which is selective and temporary. Personal priorities do vary over the life course, and even though they may become less predictable in this post-modern era, change is inevitable even as continuity and stability are sought. And leisure affords the space and time to offset the constant buzzing confusion of change at the same time it provides opportunities to experiment with new possibilities - to connect with others and/or to actualize oneself, at whatever age.

\section{REFERENCES}

Antonovsky, A. \& Sagy, S. (1990): "Confronting developmental tasks in the retirement transition", The Gerontologist, 30(3), 362-368.

Baltes, P. \& Baltes, M. (1990): "Psychological perspectives on successful aging: The model of selectiveoptimization with compensation", in P. Baltes \& M. Baltes (eds.), Successful aging: Perspectives from the behavioral sciences, Cambridge: Cambridge University Press.

Baltes, P. \& Baltes, M. M. (1998): "Savior vivre in old age: How to master the shifting balancebetween gains and losses", National Forum, 78(2), 1318.

Baltes, M. M. and Carstensen, L. L. (1996): "The process of successful aging", Aging and Society, 16, 397-422.

Barrett, L. F. \& Russell, J. A. (1999): "The structure of current affect: Controversies and emergingconsensus", Current Directions in Psychology, 8, 10-14.
Bowling, A. (2007): "Aspirations for older age in the $21^{\text {st }}$ century: What is successful aging?", International Journal of Aging and Human Development, 54(3), 263-297.

Bryant, F. \& Veroff, J. (2007): Savoring: A new model of positive experience, Mahwah, NJ: Erlbaum.

Carstensen, L. L. (1993): "Motivation for social contact across the life span: A theory of socioemotionalselectivity", in J. E. Jacobs (ed.), Developmental perspectives on motivation: Nebraska Symposiumon Motivation, Volume 40 (pp. 2090-254), Lincoln: University of Nebraska Press.

Carstensen, L. L.; Fung, H. H. \& Charles, S. T. (2003): "Socioemotional selectivity theory and theregulation of emotion in the second half of life", Motivation and Emotion, 27, 103-123.

Carstensen, L. L.; Isaacowitz, D. M. \& Charles, S. T. (1999): "Taking time seriously: A theory of socioemotional selectivity", American Psychologist, 54(3), 165-181.
Aceptado: 13 de julio de 2011 
Csikszentmihalyi, M. (1990): Flow: The psychology of optimal experience, New York: Harper Perennial.

Csikszentmihalyi, M. (1997): Finding flow: The psychology of engagement with everyday life, New York: Basic Books.

Csikszentmihalyi, M. \& Csikszentmihalyi, I. (eds.) (1988): Optimal experience: Psychological studiesof flow in consciousness, New York City: Cambridge University Press.

Deci, E. (1992): "The relation of interest to the motivation of behavior", in K. Renniger, S. Hidi, \& A. Krapp (eds.), The role of interest in learning and development (pp. 43-69), Hillsdale, NJ.

Ekerdt, D. J. (1986): "The busy ethic: Moral continuity between work and retirement", The Gerontologist, 26, 239244.

Erikson, E. (1963): Childhood and society, New York: Norton.

Erikson, E. (1982): The life cycle completed, New York: Norton.

Everard, K. M.; Lack, H. W.; Fisher, E. B. \& Baum, M. C. (2000): "Relationship of activity and socialsupport to the functional health of older adults", Journal of Gerontology, 55B, S208S212.

Folkman, S. \& Moskowitz, T. (2000): "Stress, positive emotion, and coping", Current Directions in Psychological Science, 9 115-118.

Hutchinson, S. L. \& Kleiber, D. A. (2005): "Gifts of the ordinary: Casual leisure's contribution to health andwell being", World Leisure, 47(3), 2-16.

Iwasaki, Y. \& Smale, B. J. A. (1998): "Longitudinal analyses of the relationships among life transitions, chronic health problems, leisure, and psychological well-being", Leisure Sciences, 20, 2552.

Kelly, J. R. (1987): Freedom to be: Toward a new sociology of leisure, New York, NY: Macmillan.
Katz, S. (2000): "Busy bodies: Activity, aging, and the management of everyday life", Journal of Aging Studies, 14, 135-15.

Kleiber, D. A. (1999): Leisure experience and human development, New York: Basic.

Kleiber, D. A. (2000): "The neglect of relaxation", Journal of Leisure Research, 32, 82-86.

Kleiber, D. A. (2011): "Redeeming leisure in later life", in T. Freire (ed.), Positive leisure science: Fromindividual experience to social contexts, London: Springer.

Kleiber, D. A.; Hutchinson, S. L. \& Williams, R. (2002): "Leisure as a resource in transcending negative lifeevents: Self-protection, self-restoration and personal transformation", Leisure Sciences, 24, 219-235.

Kubey, R. and Csikszentmihalyi, M. (1990): Television and the quality of life, Hilldale, NJ: Lawrence Erlbaum.

Levinson, D.; Darrow, C.; Klein, F.; Levinson, M. and McKee, B. (1978): The seasons of a man's life, New York, NY: Alfred A. Knopf.

Maynard, S. S. \& Kleiber, D. A. (2005): "Using leisure services to build social capital in later life: Classical traditions, contemporary realities, and emerging possibilities", Journal of Leisure Research, 37, 475-493.

Menec, V. H. (2003): "The relation between everyday activities and successful aging: A 6-yearlongitudinal study", Journal of Gerontology, 58, 74-82.

Musick, M. A. \& Wilson, J. (2003): "Volunteering and depression: The role of psychological and social resources in different age groups", Social Science and Medicine, 56, 259-269.

Neugarten, B. L. (1977): "Personality and aging", in J. Birren and K. W. Schaie (eds.), Handbook of the psychology of aging (pp. 626-649), New York, NY: Van Nostrand Reinhold.
Okun, M. A. \& Michel, J. (2006): "Sense of community and being a volunteer among the young-old", Journal of Applied Gerontology, 25, 173-188.

Nakamura, J. \& Csikszentmihaly, M. (2003): "The construction of meaning through vital engagement", in C. L. Keyes \& J. Haidt (eds.), Flourishing: Positive psychology and the life well-lived, Washington, DC: American Psychological Association.

Nimrod, G. (2007): "Retirees' leisure activities, benefits and their contribution to life satisfaction", Leisure Studies, $26,65-80$.

Nimrod, G. (2008): "In support of innovation theory: Innovation in activity patterns and life satisfaction among recently retired individuals", Aging \& Society, 28, 831-846.

Nimrod, G. \& Adoni, H. (2006): "Leisure styles and life satisfaction among recent retirees in Israel", Aging and Society, 26, 607-630.

Nimrod, G. \& Hutchinson, S. (2010): "Innovation among older adults with chronic health conditions", Journal of leisure Research, 42, 1-23.

Nimrod, G. \& Kleiber, D. (2007): "Reconsidering change and continuity in later life: Toward an innovationtheory of successful aging", International Journal of Aging and Human Development, 65, 1-22.

Phelan, E. A. \& Larson, E. B. (2002): "Successful Aging - Where next?", Journal of the American Geriatric Society, 50, 1306-1308.

Pieper, J. (1962): Leisure: The basis of culture, New York, NY: Pantheon Books.

Robinson, J. P. \& Godbey, G. (1997): Time for life: The surprising ways Americans use their time, University Park: PA: Pennsylvania State University Press.

Rousseau, F. L. \& Vallerand, R. J. (2008): "An examination of the relationship between passion andsubjective well- 
being in older adults", International Journal of Aging and Human Development, 66, 195-211.

Rowe, J. W. \& Kahn, R. L. (1998): Successful aging, New York: Pantheon Books.

Silvia, P. J. (2008): "Interest-The curious emotion", Current Directions in Psych. Science, 17, 57-60.

Stebbins, R. A. (1992a): Amateurs, professionals, and serious leisure, Montreal, PQ: McGill-Queen's University Press.

Stebbins, R. A. (1992b): "Costs and rewards in barbershop singing", Leisure Studies, 11, 123-134.
Stebbins, R. (2007): Serious leisure: A perspective for our time, New Brunswick, NJ: Transaction Press.

Stenseng, F. (2008): "The two faces of leisure activity engagement: Harmonious and obsessive passion inrelation to intrapersonal conflict and life domain outcomes", Leisure Sciences, 30, 465-481.

Tedeschi, R. G. \& Calhoun, L. G. (2004): "Postraumatic growth: Conceptual foundations and empirical evidence", Psychological Inquiry, 15(11), $1-18$.
Tornstam, L. (2005): Gerotranscendence: A developmental theory of positive aging, New York City: Springer Publishing.

Vaillant, G. (2002): Aging well, NYC: Little Brown.

Vallerand, R. J. (2010): "On passion for life activities: The Dualistic Model of Passion", in M. P. Zanna (ed.), Advances in experimental social psychology (Vol. 42, pp. 97-193), New York: Academic Press.

Wilson, R. (1991): "The courage to be leisured", Social Forces.. 